\title{
OPEN Improved functional properties of meat analogs by laccase catalyzed protein and pectin crosslinks
}

\author{
Kiyota Sakai ${ }^{\bowtie}$, Yukihide Sato, Masamichi Okada \& Shotaro Yamaguchi
}

The gap between the current supply and future demand of meat has increased the need to produce plant-based meat analogs. Methylcellulose (MC) is used in most commercial products. Consumers and manufacturers require the development of other novel binding systems, as MC is not chemical-free. We aimed to develop a novel chemical-free binding system for meat analogs. First, we found that laccase (LC) synergistically crosslinks proteins and sugar beet pectin (SBP). To investigate the ability of these SBP-protein crosslinks, textured vegetable protein (TVP) was used. The presence of LC and SBP improved the moldability and binding ability of patties, regardless of the type, shape, and size of TVPs. The hardness of LC-treated patties with SBP reached 32.2 N, which was 1.7- and 7.9-fold higher than that of patties with MC and transglutaminase-treated patties. Additionally, the cooking loss and water/oil-holding capacity of LC-treated patties with SBP improved by up to $8.9-9.4 \%$ and $5.8-11.3 \%$, compared with patties with MC. Moreover, after gastrointestinal digestion, free amino nitrogen released from LC-treated patties with SBP was 2.3-fold higher than that released from patties with MC. This is the first study to report protein-SBP crosslinks by LC as chemical-free novel binding systems for meat analogs.

In the last two decades, there has been a 58\% growth in the global demand for meat due to an increase in the global population and rapid development of economy ${ }^{1}$. Moreover, the global population is expected to reach 9.7 billion by 2050 , which will lead to a greater increase in protein demand ${ }^{2}$. However, limited land and water resources for livestock farming sustainability, rapid increase in animal welfare issues, undesirable effects on the environment, and change in climate have made it difficult to increase meat production to meet the future demand ${ }^{3}$. Thus, there is a gap between the present supply and future demand of meat; consequently, there is an increasing need to produce plant-based meat analogs as protein sources. Fresán and Sabaté reported that along with environmental benefits, human health benefits could also be achieved by changing the current dietary patterns to plant-based diets ${ }^{4}$. Moreover, to meet the demands of the expanding kosher and halal markets, it is necessary to develop plant-based meat analogs, instead of livestock-based or cell-based meat ${ }^{5}$. By 2025 , more than $30 \%$ of the world's population may consume these types of food ${ }^{5}$, making plant-based meat analogs one of the most popular topics within food and research communities.

Meat analogs are principally composed of textured vegetable proteins (TVPs) that imitate the fibrillar structure of meat muscle ${ }^{6}$. Soy-based TVP is a plant-based protein product that is cholesterol-free, with low concentrations of saturated fat and high concentrations of essential amino acids; it has several economical and functional benefits ${ }^{7,8}$. Soy-based TVP also presents characteristic functional properties, such as a high water holding capacity (WHC) and a good gelling behavior, fat absorption, and emulsification capacities ${ }^{9}$. It has been reported that when soy protein is used as a TVP constituent, the final product could mimic the texture, appearance, taste, smell, and functionality of red meat ${ }^{5}$.

The presence of binders is of importance as TVPs have no binding ability, considerably affecting the palatability of the final analog. Currently, methyl cellulose (MC) is used in most commercial products ${ }^{10}$ as it is a cheap binder and is considered safe for human consumption ${ }^{11,12}$. However, MC is chemically synthesized from cellulose and chloromethane in the presence of concentrated sodium hydroxide solution and is the main active ingredient in various laxatives. Therefore, concerns of MC not being a chemical-free binder and related risks necessitate the development of novel chemical-free binding systems for consumers and manufacturers. Moreover, the physical properties of existing plant-based meat analogs are still inferior to those of animal-based meat, especially when 
referring to texture, hardness, and juiciness ${ }^{10,13}$. These properties are crucial for the consumers' acceptance of food products and, hence, remain a critical obstacle ${ }^{13}$. Another challenge for plant-based meat analogs is the presence of anti-nutritional factors, such as protease inhibitors, tannins, and phytates. These factors decrease the digestibility and bioavailability of plant proteins compared with animal proteins ${ }^{10,13}$. Based on the above issue, there are many remaining challenges in making plant-based meat analogs available to a wide range of consumers.

Protein crosslinks can be introduced into food matrices using chemical, enzymatic, and physical methods ${ }^{14-16}$. Among these approaches, transglutaminase (EC 2.3.2.13, TG) improves the physical properties of various protein-based foods ${ }^{17,18}$. This enzyme catalyzes the formation of an isopeptide bond between the glutamine residue side chains and lysine residue side chains ${ }^{18}$. Laccase (EC 1.10.3.2, LC) is also a protein-crosslink enzyme ${ }^{19}$. It oxidizes tyrosine phenols via a one-electron removal mechanism, producing phenoxy radicals. In proteins, the exposed tyrosyl side chains serve as substrates for oxidation by LC, resulting in the spontaneous production of subsequent protein crosslinks (dityrosine) ${ }^{15,19-22}$. However, the crosslinking reaction by LC oxidation cannot improve the physical properties of foods because proteins are poor substrates for $\mathrm{LC}^{15,20,23,24}$. Therefore, only TG has been commercially used as a crosslinking enzyme in the food industry.

Sugar beet pectin (SBP) consists of a linear $\alpha$-1,4-D-galacturonic acid residue backbone, containing neutral sugars and ferulic acid, which are esters linked to arabinose and galactose side chains in the hairy region ${ }^{25,26}$. Approximately 50-60\% of ferulic acid groups are linked to the backbone of the arabinan side chains, whereas the rest are linked to galactose residues ${ }^{27}$. Traditionally, SBP has been used in the food industry as an emulsifying, thickening, and stabilizing agent ${ }^{26,28}$; it also forms stable gels by oxidative coupling and covalent crosslinks between beet pectin molecules via oxidative enzymes, such as LC and peroxidase ${ }^{29,30}$. The presence of covalent crosslinks in gels prevents post-gelation structural rearrangement and associated syneresis. As the crosslinks introduced by LC are heat-stable, firmness and elasticity can be retained ${ }^{29}$. This hydrogel is thermo-irreversible ${ }^{31}$, which is a significant feature for food, biomedical, and biopharmaceutical applications ${ }^{32}$. So far, the use of an LC-catalyzed protein-SBP crosslink as a potential novel binding system for plant-based meat analogs has not been reported.

In this study, we aimed to develop a novel chemical-free binding system for meat analogs and to solve the physical and nutritional shortcomings of meat analogs. SBP was used as a mediator to improve the ability of LC to crosslink protein-based foods. First, we investigated whether TVP-SBP crosslinks formed by LC could become a novel binding system for meat analogs. As a result, the presence of LC and SBP improved the moldability and binding ability of patties, regardless of the type, shape, and size of TVPs. Moreover, compared with MC, LC-catalyzed protein-SBP crosslinks reduced the cooking loss and improved the water/oil holding capacity and gastrointestinal digestibility of meat analog patties. These findings indicate that TVP-SBP crosslinks formed by LC improved physical and nutritional properties, potentially solving the current challenges faced by plantbased meat analogs.

\section{Results and discussion}

Synergistic effect of LC on the formation of protein and SBP crosslinks. Soy protein solution, SBP solution, and soy protein + SBP solution were incubated with 100 units of LC for $20 \mathrm{~min}$ at $40{ }^{\circ} \mathrm{C}$. As shown in lane 4, protein-SBP crosslinks were too large to enter the acrylamide gel (Fig. 1a). However, as shown in lanes 2 and 3, protein-protein crosslinks and SBP-SBP crosslinks were not induced by the LC reaction (Fig. 1a). The viscosity of the soy protein solution, SBP solution, and soy protein + SBP solution treated with LC was then measured. Although the viscosity of soy protein solution and SBP solution treated with LC did not change, the viscosity of soy + SBP solution treated with LC increased in a time-dependent manner (Fig. 1b). The soy + SBP solution treated with LC was finally gelled. These findings indicated that protein and SBP crosslinks were synergistically catalyzed by LC, leading to changes in their physical properties.

SBP gelation catalyzed by LC requires a longer incubation time and higher concentration of oxidation enzymes $^{29,33}$. Previous studies have reported that proteins, such as fish gelatin, soy protein isolate, and whey protein isolate, can be crosslinked with SBP by oxidation enzymes ${ }^{34-36}$. As shown in Fig. 1c, LC can oxidize ferulic acid and tyrosine, leading to protein-SBP crosslinks ${ }^{37,38}$. This combination of SBP and protein provided additional properties to hydrogels and shortened the gelling time ${ }^{29,33-39}$. In this study, protein-SBP crosslinks were also formed by LC oxidation (Fig. 1a,b). Therefore, as a novel binding system for meat analogs, this protein-SBP gel could help develop food products with additional textural properties.

Improving physical properties of meat analogs by SBP-protein crosslinks. To investigate whether SBP-protein crosslinks formed by LC oxidation could be a novel binder for meat analogs, soy-based TVP and SBP were incubated with LC. MC was used as the control. Figure 2a shows the meat analog patties after incubation and cooking. Non-treated and LC-treated meat analog patties without a binder collapsed after incubation and grilling. Meat analog patties containing MC maintained their shapes with or without enzymes after grilling. Interestingly, LC-treated meat analog patties containing SBP maintained their shape after grilling. In contrast, non-treated meat analog patties containing SBP collapsed after incubation and cooking. Moreover, various plant-based TVPs were incubated with SBP and LC under the same conditions (Supplementary Figs. S2 and S3). The results revealed that the presence of LC and SBP improved the moldability and binding ability of meat analog patties, regardless of the type, shape, and size of TVPs.

The hardness of the meat analog patties after grilling was investigated using a rheometer (Fig. 2b). The hardness of patties containing MC was substantially higher in the order TG- > LC- > non-treated. Interestingly, the hardness of LC-treated patties containing SBP was substantially higher than that of non- and LC-treated patties containing MC. Moreover, as shown in Fig. 3, the hardness of meat analog patties was enhanced in an LC and SBP concentration- and time-dependent manner. The hardness of LC-treated patties with SBP plateaued at 
a

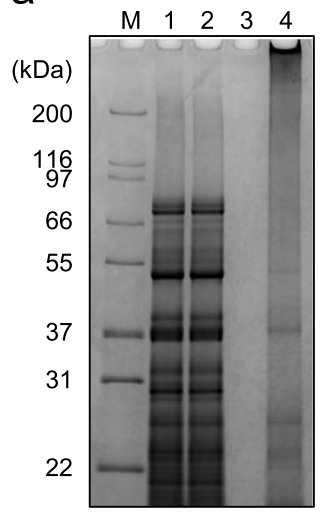

b

C

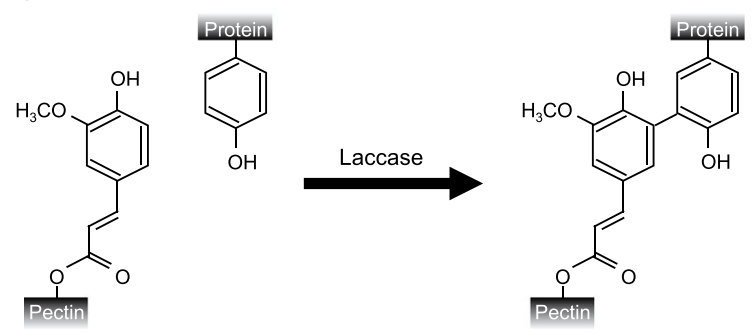

Figure 1. Synergistic effects of LC-catalyzed oxidative reaction on the formation of protein and SBP crosslinks. (a) SDS-PAGE analysis of soy protein and SBP treated with $100 \mathrm{U}$ LC. Lane 1, non-treated soy protein and SBP; Lane 2, LC-treated soy protein; Lane 3, LC-treated SBP, Lane 4, LC-treated soy protein and SBP. Full-length SDS-PAGE gels are presented in Supplementary Fig. S1. (b) Apparent viscosity of soy protein and SBP solution treated with LC was measured using a viscometer. Open circle, LC-treated SBP; closed circle, LC-treated soy protein; blue circle, LC-treated soy protein and SBP. (c) Schematic of protein-SBP crosslink formation via LC-catalyzed oxidative reaction.

32.2 $\mathrm{N}$ after $4 \mathrm{~h}$ of LC reaction, which was 1.7- and 7.9-fold higher than that of patties with MC and TG-treated patties. These findings indicate that TVP-SBP crosslinks offer great promise in changing the physical properties of plant-based meat analog products.

Table 1 shows the TPA parameters (hardness, cohesiveness, springiness, and chewiness) of enzyme-treated meat analog patties containing binders. The chewiness of these patties was substantially higher in the order LCtreated patties with SBP > non-treated and LC-treated patties with MC $>$ TG-treated patties. The hardness and chewiness of LC-treated patties increased in a SBP concentration-dependent manner, whereas the cohesiveness and springiness did not change. Our finding that the hardness and chewiness of LC-treated patties increased in an SBP concentration-dependent manner is similar to that of previous studies that incorporated other binders into patties. These previous studies reported that increasing concentration of binders such as MC and carrageenan proportionally increases the hardness and chewiness of products ${ }^{7,40-42}$. The hardness of LC-treated patties containing SBP was lower than that of animal-based patties containing $\mathrm{MC}^{40}$. Meat protein generally presents a higher degree of shrinkage. Therefore, the higher hardness of animal-based patties has been suggested to be due to muscle protein denaturation, which led to meat hardening ${ }^{40,43}$. Whereas, the hardness and chewiness of LC-treated patties containing SBP were similar to or higher than those of meat analogs containing other binders reported previously $1,40,41,44$. These findings suggest that TVP-SBP crosslinks formed by LC oxidation are a novel binder for meat analog patties. This is the first report of enhancing the moldability and binding ability of patties by TVP-SBP crosslinks by LC.

Improving physical properties of meat analogs by MC. In this study, MC was used as the control in all experiments. The mechanism by which gelation between MC and protein is achieved remains unclear. One standard theory is that the hydrophobic methyl groups of MC are surrounded by cage-like structures of water molecules ${ }^{45}$. However, with increasing temperature, the cage structure is disrupted, and the polymers gradually lose water ${ }^{46,47}$. At elevated temperatures, MC prefers hydrophobic association states, leading to the formation of strong gels ${ }^{46,47}$; the results of this study are consistent with those reported previously (Figs. 2b, 4). After grilling, the cooking loss and holding capacity of patties decreased, indicating the release of water. In contrast, the hardness of patties that had MC increased. Moreover, all TPA parameters of the LC- and TG-treated patties containing MC were higher than those of non-treated patties containing MC (Table 1). These findings suggest that TPA parameters of the patty are synergistically enhanced by crosslinking enzymes such as LC and TG.

Currently, $\mathrm{MC}$ is used in most of the commercial products ${ }^{10}$. However, only a few studies have reported the effects of MC on the physical and functional characteristics of plant-based meat analog patties ${ }^{40}$. In this study, 
a

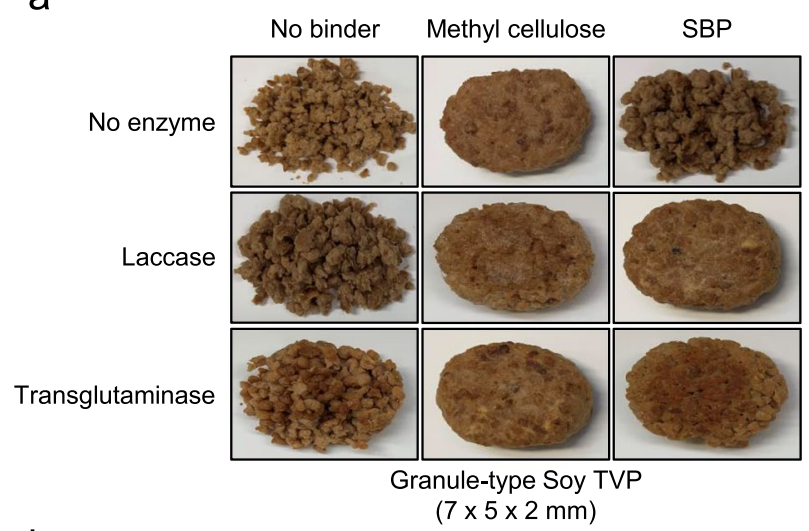

b

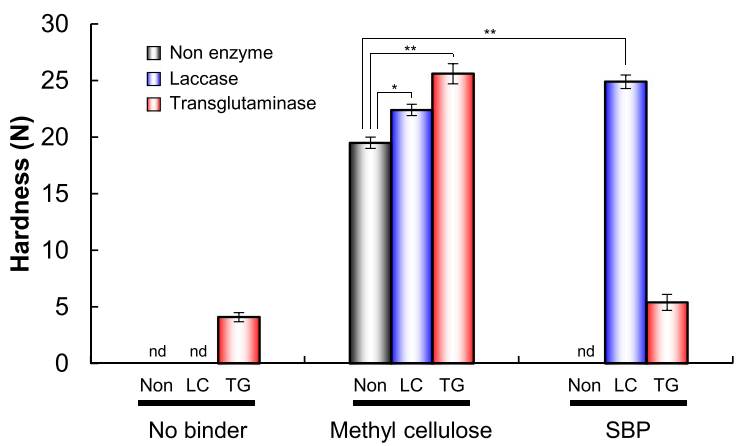

Figure 2. Appearance of grilled meat analogs treated with enzyme. (a) Meat analogs were treated with 20 U/g-TVP LC and 50 U/g-TVP TG, in the presence or absence of a binder (MC or SBP). (b) The hardness of meat analogs treated with each enzyme was measured using a rheometer. Data are presented as mean \pm standard deviation of five experiments. ${ }^{*} p<0.05,{ }^{* *} p<0.01$, Student's $t$-test. Non, non-treated meat analogs; LC, LC-treated meat analogs; TG, TG-treated meat analogs.

a

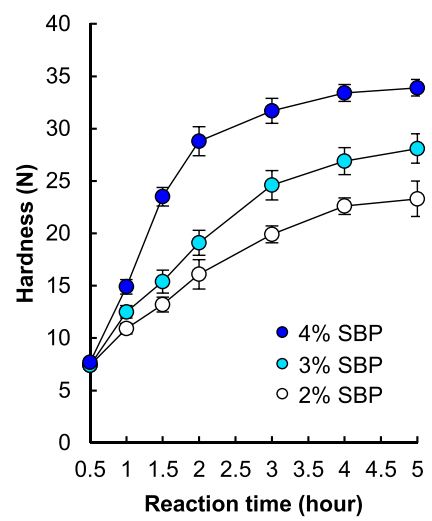

b

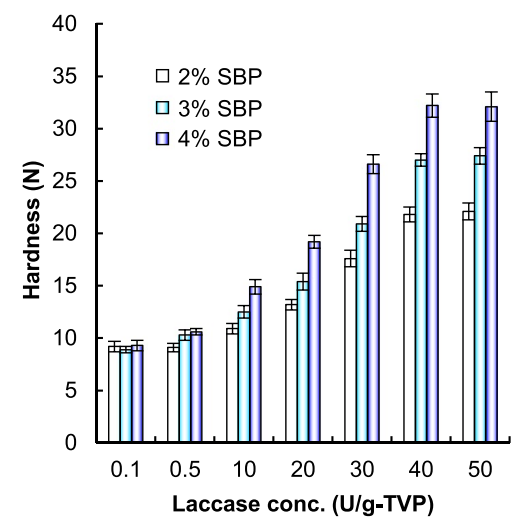

Figure 3. Hardness of grilled meat analog patties treated with LC. The hardness of the meat analogs treated with LC was measured using a rheometer. (a) Meat analogs containing 2-4\% SBP were treated with 20 U/g-TVP LC at $0.5-4.0 \mathrm{~h}$. (b) Meat analogs containing 2-4\% SBP were treated with various concentrations of LC. Data are presented as mean \pm standard deviation of five experiments.

we investigated the properties of MC as a control binder, in detail. Selecting the right binder and its amount for meat analog products is crucial ${ }^{10,40,48}$. Therefore, the findings on patties containing MC expand our knowledge on their physical properties. This study will also contribute to a better understanding of the functional roles of MCs.

Cooking loss and water/oil holding capacity of meat analog patties. Cooking loss represents the degree of meat shrinkage during cooking, which is an important indicator for evaluating the juiciness and yield 


\begin{tabular}{|c|c|c|c|c|c|c|c|}
\hline Binder & Conc. & LC & TG & Hardness (N) & Cohesiveness & Springiness & Chewiness (N) \\
\hline \multirow{2}{*}{ MC } & \multirow{2}{*}{$2 \%$} & $0 \mathrm{U} / \mathrm{g}-\mathrm{TVP}$ & \multirow{2}{*}{-} & $18.4 \pm 0.6$ & $0.70 \pm 0.04$ & $0.71 \pm 0.05$ & $9.1 \pm 0.5$ \\
\hline & & $20 \mathrm{U} / \mathrm{g}$-TVP & & $21.5 \pm 0.9$ & $0.77 \pm 0.03$ & $0.81 \pm 0.08$ & $13.4 \pm 0.7$ \\
\hline \multirow{3}{*}{ SBP } & $2 \%$ & \multirow{3}{*}{$20 \mathrm{U} / \mathrm{g}-\mathrm{TVP}$} & \multirow{3}{*}{-} & $21.8 \pm 0.3$ & $0.78 \pm 0.05$ & $0.80 \pm 0.05$ & $13.6 \pm 0.4$ \\
\hline & $3 \%$ & & & $23.6 \pm 0.5$ & $0.77 \pm 0.09$ & $0.78 \pm 0.07$ & $14.2 \pm 0.7$ \\
\hline & $4 \%$ & & & $25.5 \pm 0.7$ & $0.79 \pm 0.07$ & $0.77 \pm 0.06$ & $15.6 \pm 1.2$ \\
\hline Non & - & \multirow{3}{*}{-} & \multirow{3}{*}{$50 \mathrm{U} / \mathrm{g}-\mathrm{TVP}$} & $7.1 \pm 0.3$ & $0.51 \pm 0.06$ & $0.57 \pm 0.09$ & $2.1 \pm 0.3$ \\
\hline $\mathrm{MC}$ & $2 \%$ & & & $23.1 \pm 0.3$ & $0.79 \pm 0.08$ & $0.77 \pm 0.07$ & $14.1 \pm 0.7$ \\
\hline SBP & $2 \%$ & & & $10.2 \pm 0.4$ & $0.57 \pm 0.09$ & $0.64 \pm 0.08$ & $3.7 \pm 0.7$ \\
\hline
\end{tabular}

Table 1. Texture profile analysis of meat analogs. Meat analogs were treated with $20 \mathrm{U} / \mathrm{g}$-TVP LC or $50 \mathrm{U} / \mathrm{g}$ TVP TG in the presence of MC or sugar beet pectin. Data are presented as mean \pm standard deviation of five experiments.

a

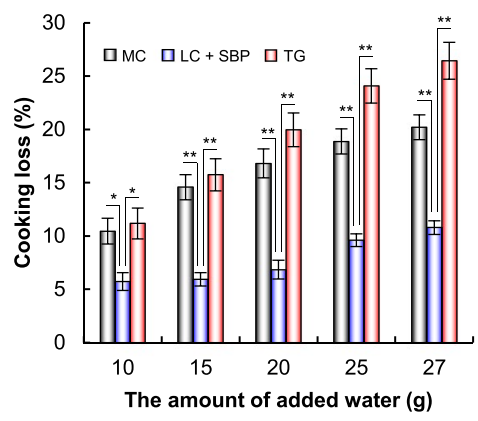

C

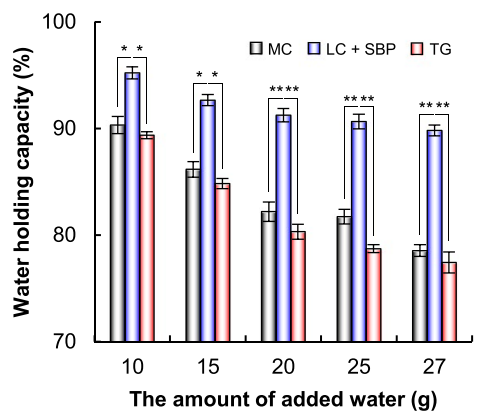

b

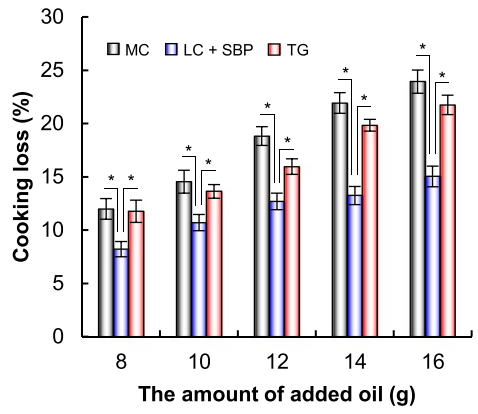

d

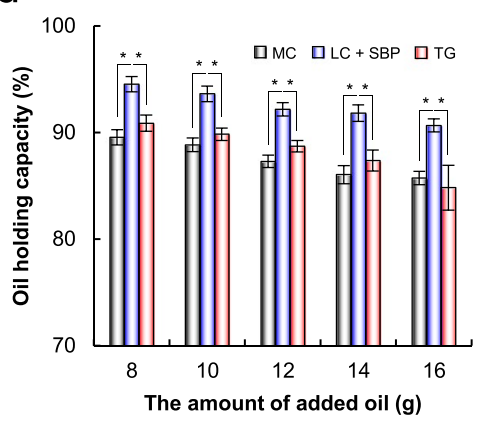

Figure 4. Cooking loss value and water/oil holding capacity of meat analogs. (a, b) Cooking loss was calculated as the percentage weight difference between the dough before cooking and after cooking. Meat analog containing different amounts of water (a) or oil (b) was treated with LC and cooked. (c, d) Holding capacity was calculated by comparing the weight of meat analogs before and after centrifugation. Meat analog patties containing different amounts of water (c) or oil (d) was treated with LC, cooked, and centrifuged. ${ }^{*} p<0.05$, ${ }^{* *} p<0.01$, Student's $t$-test. MC, meat analog containing MC; LC +SBP, LC-treated meat analog containing SBP; TG, TG-treated meat analog.

of the final product. As the amount of water and oil increased, a typical increase in the cooking loss of all patties was observed (Fig. 4a,b). Surprisingly, the cooking loss of LC-treated patties containing SBP was substantially lower than that of patties containing MC and TG-treated patties. When adding various amounts of water and oil, the cooking loss of LC-treated patties with SBP decreased by up to $8.9-9.4 \%$ and $6.7-15.6 \%$ compared with patties with MC and TG-treated patties, respectively. Water and oil holding capacity is an important factor, as it affects the quality and yield of fresh patties or their products ${ }^{49}$; the higher the holding capacity of patties, the more the juiciness. As the amount of water and oil increased, the water and oil holding capacity of all patties showed a typical decrease (Fig. 4c,d). The water and oil holding capacity of LC-treated patties containing SBP was substantially higher than that of patties containing MC and TG-treated patties. When adding various amounts of water and oil, the water and oil holding capacity of LC-treated patties with SBP increased by up to 5.8-11.3\% and 5.8-12.4\% compared with patties with MC and TG-treated patties, respectively. These findings indicate that TVP-SBP crosslinks catalyzed by LC are superior to the high-network formed by MC, indicating that LC-treated patties containing SBP were juicier. 
a

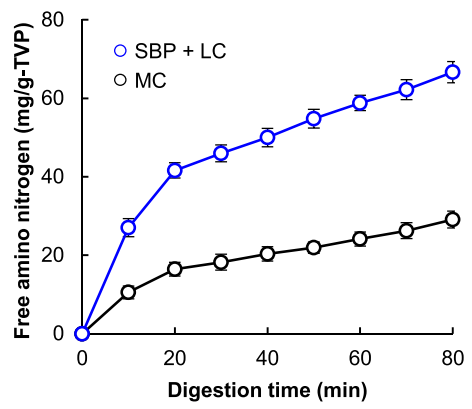

b

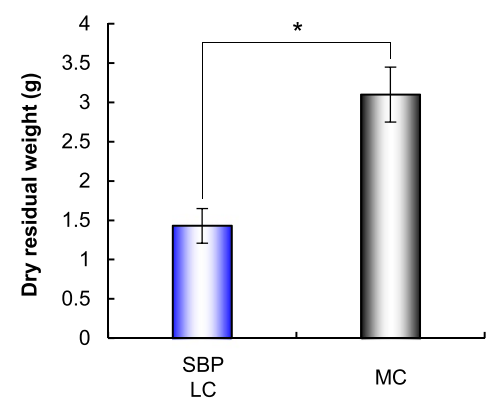

Figure 5. In-vitro gastrointestinal digestibility of meat analogs. The gastrointestinal digestion test was performed for $90 \mathrm{~min}$. Free amino nitrogen released from meat analogs (a) was measured using the ninhydrin method, and then its dry residual weight $(\mathbf{b})$ was measured. Data are presented as mean \pm standard deviation of three experiments. ${ }^{*} p<0.05$, Student's $t$-test.

MC is an effective amphiphilic cellulose derivative with the ability to absorb high amounts of water and oil $^{40,50,51}$. In this study, the cooking loss and holding capacity of patties were more enhanced by LC-catalyzed protein-SBP crosslinks than by the high-network formed by MC (Fig. 4). SBP also has good amphiphilic properties, contributed by the protein moiety ferulate and acetyl groups, which impart hydrophobic properties, and the carbohydrate fraction, which imparts hydrophilic properties ${ }^{52,53}$. Oxidative enzymes, such as LC and peroxidase, can form a hydrated network, leading to hydrogel formation with a high water-holding capacity ${ }^{30}$. Here, the water holding capacity of patties was in the order of SBP + LC > MC (Fig. 4a,c), suggesting that TVP-SBP crosslinks formed a hydrogel-like network and improved the water retention capacity of plant-based meat analog patties.

LC treatment is an effective approach to prepare stable multilayered emulsions as it can crosslink proteins and SBP, and shrink the droplet size $\mathrm{s}^{545}$. A previous study reported that an LC-treated multilayered proteinSBP stabilized emulsion improves emulsifiability compared with a non-treated protein and SBP emulsion ${ }^{56}$. Moreover, emulsions treated with LC and SBP exhibit droplets with a tight protein-polysaccharide membrane, higher emulsification stability during heating, oil retention, and freeze-thaw cycles, and at a wide $\mathrm{pH}$ range ${ }^{54-56}$. The results of this study are consistent with those reported previously; the oil holding capacity of patties was in the order SBP + LC $>$ SBP + TG > MC + TG > MC > TG (Fig. 4; Supplementary Fig. S4). It is considered that LC formed a multilayered protein-SBP-stabilized emulsion and enhanced the emulsion stability and oil retention capacity of plant-based meat analog patties.

In-vitro gastrointestinal digestibility of meat analogs. Figure 5 shows free amino nitrogen released from the plant-based meat analog patty and its dry residual weight after in-vitro gastrointestinal digestion by pepsin. The amount of free amino nitrogen released from LC-treated patties containing SBP was 2.3-fold higher than that from patties containing MC (Fig. 5a). The dry residual weight of LC-treated patties containing SBP was 2.2-fold lower than that of patties containing MC (Fig. 5b). These findings indicated that LC-treated patty containing SBP was easier to digest with pepsin and absorb nutrients from. This is considered to be because of higher water holding capacity, cohesiveness, and springiness (Fig. 4 and Table 1). Cohesiveness and springiness are the extent to which the gel withstands a second deformation relative to its resistance under the first deformation. Generally, the higher the water retention, cohesiveness, and springiness, the lower the density of food fragments after chewing. Therefore, the dispersibility of LC-treated patties containing SBP in the imitated gastric juice was considered to be high, leading to an enhanced pepsin activity toward the patties.

Meat as a protein source provides humans with the necessary nutrients and energy to function throughout the day ${ }^{57}$. Generally, meat analogs are considered to have slightly lower protein content than traditional meat products $^{10,13}$. However, the digestibility of plant proteins is lower than that of animal-derived proteins because of different factors ${ }^{58}$. According to a previous study, all processing conditions, such as heat treatment, high pressure, $\mathrm{pH}$ change, protein fractionation, enzymatic reaction, milling, pressure, and fermentation, affect the nutritional availability of amino acids from proteins ${ }^{59}$. Here, replacing MC with TVP-SBP crosslinks catalyzed by $\mathrm{LC}$ as a binding system enhanced the digestibility of plant-based meat analog patties (Fig. 5a). Therefore, TVP-SBP crosslinks catalyzed by LC offer an option to overcome the poor nutritional availability of amino acids from plant-based meat analogs.

Based on recent scientific efforts, numerous studies have indicated the health benefits associated with the replacement of animal sources of protein with plant-based proteins, including reduced risks of type 2 diabetes, heart disease, and stroke $e^{60,61}$. Additionally, dietary fiber in meat analogs is considered to play an essential role in preventing large bowel disease, ischemic heart disease, and diabetes mellitus ${ }^{62}$. MC is a chemically modified polysaccharide, and this has raised concerns among the consumers and manufacturers as it is not a chemicalfree binder. The SBP used in this study was a natural and chemical-free polysaccharide. Therefore, SBP offers great promises in not only enhancing physical and functional properties of patty but also improving nutritional availability and disease prevention. 


\section{Materials and methods}

Materials. Granule-type, fillet-type, chunk-type, and slice-type soy-based TVPs were purchased from Marukome Co., Ltd. (Nagano, Japan). Granule-type, strip-type, and slice-type pea-based TVPs were obtained from Puris LLC (Minneapolis, USA), SANSHO Co., Ltd. (Tokyo, Japan), and AJIGEN Co., Ltd. (Kagawa, Japan), respectively. Slice-type gluten-based TVP was purchased from Saniku Foods Co., Ltd. (Chiba, Japan).

SDS-PAGE analysis of crosslink. To investigate the synergistic effect of LC on the formation of SBP and protein crosslinks, the degree of crosslinking was measured by SDS-PAGE under reducing conditions with dithiothreitol (DTT). Assay of $10 \%(\mathrm{v} / \mathrm{v})$ soy solution, $0.5 \%(\mathrm{v} / \mathrm{v})$ SBP solution, and $10 \%(\mathrm{v} / \mathrm{v})$ soy $+0.5 \%(\mathrm{v} / \mathrm{v})$ SBP solutions was performed in reaction mixtures containing phosphate buffer $(100 \mathrm{mM}, \mathrm{pH} 7.0)$ and LC (100 units). The reaction mixtures were incubated at $40{ }^{\circ} \mathrm{C}$ for $20 \mathrm{~min}$, and the reaction was terminated by boiling at $100{ }^{\circ} \mathrm{C}$ for $5 \mathrm{~min}$.

Rheological characterization. The viscosity of the soy solution, SBP solution, and soy + SBP solutions was measured using EMS-1000 (Kyoto Electronics Manufacturing Co., Ltd., Tokyo, Japan). Each solution was assayed in reaction mixtures containing phosphate buffer (100 mM, pH 7.0) and LC (500 units). The shear rate applied to the samples was $200 \mathrm{~s}^{-1}$, and a preliminary measurement was conducted for $30 \mathrm{~s}$ to maintain the flow conditions. The temperature of the samples was set to $40{ }^{\circ} \mathrm{C}$ during the measurements. The variation in protein and SBP concentrations due to water vaporization was confirmed by gravimetric measurements.

Preparation for plant-based meat analogs. The base of the TVP matrix was prepared using TVPs and a binder (MC or SBP), followed by the addition of olive oil and enzyme solution additives (Table S1). First, dried TVP was immersed in water (five times in volume) for $2 \mathrm{~h}$ for hydration. After dehydrating the swollen TVP, it was mixed $2.0-4.0 \% \mathrm{SBP}$ or $2.0 \% \mathrm{MC}$ at the final concentration. Unless otherwise noted, the TVP matrix was prepared in the absence and presence of $2.0 \%$ (final concentration) binder. Thereafter, different amounts of water or olive oil were added to each $25 \mathrm{~g}$ of TVP matrix. These were blended for $60 \mathrm{~s}$ using a hand blender. Thereafter, LC (LC-Y120; Amano Enzyme Inc., Nagoya, Japan) was added to the TVP matrix and blended for $60 \mathrm{~s}$. LC used in this study was a commercially available food-grade product. According to the instruction manual of the manufacturer, the optimal reaction temperature for $\mathrm{LC}$ is $60^{\circ} \mathrm{C}$, with a preferred temperature range between 25 and $80^{\circ} \mathrm{C}(>65 \%)$. The TVP matrix was molded in a cylindrical mold (60 $\mathrm{mm} \times 40 \mathrm{~mm}$ area and $25 \mathrm{~mm}$ height) and incubated at $25^{\circ} \mathrm{C}$ for $4 \mathrm{~h}$. The matrix was then cooked in an oven at $200{ }^{\circ} \mathrm{C}$ for $15 \mathrm{~min}$ and cooled to room temperature $\left(20-25^{\circ} \mathrm{C}\right)$ before being used for further analysis.

Texture profile analysis. Texture profile analysis (TPA) was carried out using COMPAC-100II (Sun Scientific Co., Ltd., Tokyo, Japan) equipped with a cylindrical probe with an area of $31.4 \mathrm{~mm}$. Meat analog patties were treated with 0.1-50 U/g-TVP LC and 50 U/g-TVP TG, respectively. Unless otherwise noted, it was performed with $20 \mathrm{U} / \mathrm{g}$-TVP LC $(5.0 \mathrm{mg})$. After grilling, meat analogs were prepared for the analysis and cut to a length of $15 \mathrm{~mm}$ to obtain homogeneous extrudates. The diameter of each extrudate was approximately $20 \mathrm{~mm}$. A double compression cycle was performed at $1 \mathrm{~mm} / \mathrm{s}$ until a recorded deformation of $50 \%$ was achieved. The following parameters were evaluated: hardness, the maximum force recorded during the first compression; cohesiveness, the area of work during the second compression divided by the area of work during the first compression; springiness, the distance recorded during the second compression divided by the distance of the first compression; and chewiness, hardness $\times$ cohesiveness $\times$ springiness.

Cooking loss. The cooking method and conditions were determined based on the study of Pathare and Roskully ${ }^{63}$. The patties were cooked at $200^{\circ} \mathrm{C}$ for $15 \mathrm{~min}$, depending on the temperature at the center of the meat analog, reaching $80^{\circ} \mathrm{C}$. After cooking, the samples were cooled to room temperature $\left(20-25^{\circ} \mathrm{C}\right)$. Cooking loss was calculated as the percentage weight difference between the patty before cooking and after cooking, using the following formula: cooking loss $(\%)=\left(\left(\mathrm{W}_{1}-\mathrm{W}_{2}\right) / \mathrm{W}_{1}\right) \times 100 ; \mathrm{W}_{1}$ : weight of the meat analog before grilling $(\mathrm{g})$, $\mathrm{W}_{2}$ : weight of the meat analog after grilling $(\mathrm{g})$.

Water/oil holding capacity. Water holding capacity and oil holding capacity were measured by modifying a previously described method ${ }^{64,65}$. Briefly, grilled meat analog $(5 \mathrm{~g})$ was placed in a 50 -mL tube with gauze underneath. The tube was then centrifuged at $3,000 \mathrm{~g}$ for $10 \mathrm{~min}$ at $35^{\circ} \mathrm{C}$. Holding capacity $(\mathrm{HC})$ was calculated by comparing the weight of the meat analogs before and after centrifugation using the following formula: HC $(\%)=\left(\mathrm{W}_{2} / \mathrm{W}_{1}\right) \times 100 ; \mathrm{W}_{1}$ : weight of the meat analog before centrifugation $(g), \mathrm{W}_{2}$ : weight of the meat analog after centrifugation $(g)$.

In-vitro gastrointestinal digestibility of meat analogs. In-vitro gastrointestinal digestion tests were performed in $130-\mathrm{mL}$ reaction mixtures containing $\mathrm{NaCl}(4.39 \mathrm{~g}), \mathrm{KCl}(0.22 \mathrm{~g}), \mathrm{CaCl}_{2}(0.04 \mathrm{~g}), \mathrm{Mcll}_{\text {vaine buffer }}$ ( $\mathrm{pH} 5.0$ ), meat analogs ( $25 \mathrm{~g}$, finely cut), and $0.0065 \%$ pepsin from porcine gastric mucosa (Sigma-Aldrich, St. Louis, MO, USA). The digestive reaction mixtures were incubated at $37^{\circ} \mathrm{C}$ and $60 \mathrm{rpm}$ for $90 \mathrm{~min}$, and $1 \mathrm{~N} \mathrm{HCl}$ was added to the reaction mixtures every $5 \mathrm{~min}$, resulting in pH 3.0 after $40 \mathrm{~min}$. The solution was clarified using a Nanosep ${ }^{\oplus}$ Centrifugal Device (Pall Corporation, Port Washington, NY, USA) as described in the instruction manual. The free amino nitrogen was measured using the ninhydrin method ${ }^{66}$. 


\section{Conclusions}

In this study, the synergistic effects of TVP and SBP crosslinks catalyzed by LC, on the physical and nutritional properties of meat analogs were investigated. The presence of LC and SBP improved the moldability and binding ability of meat analog patties, regardless of the type, shape, and size of TVPs. The hardness of the LC-treated patties plateaued at $32.2 \mathrm{~N}$, indicating that TVP-SBP crosslinks formed by LC were superior to those formed by MC. In addition, the water/oil holding capacity of LC-treated patties containing SBP was substantially higher than that of patties containing MC. This indicates that LC-treated patties containing SBP were juicier. Moreover, the amount of free amino nitrogen released from LC-treated patties containing SBP was 2.3-fold higher than that from patties containing MC after in vitro gastrointestinal digestion. It is considered that LC-treated patties containing SBP are easier to digest using pepsin and absorb nutrients from. This study is the first to show that this protein-SBP crosslink catalyzed by LC could be a binding system for plant-based meat analogs.

\section{Data availability}

All data generated or analyzed during this study are included in this published article and supplementary information.

Received: 22 May 2021; Accepted: 4 August 2021

Published online: 17 August 2021

\section{References}

1. Whitnall, T. \& Pitts, N. Global trends in meat consumption. Agric. Commod. 9, 96-99 (2019).

2. United Nations-Department of Economic and Social Affairs-Population Division 2019. World Population Prospects 2019: Highlights (ST/ESA/SER.A/423); United Nations: New York, NY, USA, 2019; pp. 37-38. https://population.un.org/wpp/Publications/ Files/WPP2019_Highlights.pdf. Accessed 15 June 2020.

3. Alexander, P. et al. Could consumption of insects, cultured meat or imitation meat reduce global agricultural land use?. Glob. Food. Sec. 15, 22-32 (2017).

4. Fresán, U. \& Sabaté, J. Vegetarian diets: Planetary health and its alignment with human health. Adv. Nutr. 10, S380-S388 (2019).

5. Asgar, M. A., Fazilah, A., Huda, N., Bhat, R. \& Karim, A. A. Nonmeat protein alternatives as meat extenders and meat analogs. Compr. Rev. Food Sci. Food Saf. 9, 513-529 (2010).

6. Caporgno, M. P. et al. Extruded meat analogues based on yellow, heterotrophically cultivated Auxenochlorella protothecoides microalgae. Innov. Food Sci. Emerg. Technol. 59, 102275 (2020).

7. Arora, B., Kamal, S. \& Sharma, V. Effect of binding agents on quality characteristics of mushroom based sausage analogue. J. Food Process. 41, e13134 (2017).

8. Ranasinghesagara, J., Hsieh, F. H. \& Yao, G. An image processing method for quantifying fiber formation in meat analogs under high moisture extrusion. J. Food Sci. 70, 450-454 (2005).

9. Kyriakopoulou, K., Dekkers, B., \& van der Goot, A.J. Plant-based meat analogues. In Sustainable Meat Production and Processing (ed. Galanakis C. M.), Academic Press, Cambridge, MA, USA. 103-126. Elsevier Inc. (2019).

10. Bohrer, B. M. An investigation of the formulation and nutritional composition of modern meat analogue products. Food Sci. Hum. Wellness 8, 320-329 (2019).

11. Al-Tabakha, M. M. HPMC capsules: Current status and future prospects. J. Pharm. Pharm. Sci. 13, 428-442 (2010).

12. Bampidis, V. et al. Safety and efficacy of methyl cellulose for all animal species. EFSA J. 18, 6212 (2020).

13. Lee, H. J., Yong, H. I., Kim, M., Choi, Y. S. \& Jo, C. Status of meat alternatives and their potential role in the future meat market - A review. Asian J. Anim. Sci. 33, 1533-1543 (2020).

14. Singh, H. Modification of food proteins by covalent crosslinking. Trends Food Sci. Technol. 2, 196-200 (1991).

15. Buchert, J. et al. Crosslinking food proteins for improved functionality. Annu. Rev. Food Sci. Technol. 1, 113-138 (2010).

16. Gerrard, J. A. Protein-protein cross-linking in food: methods, consequences, applications. Trends Food Sci. Technol. 13, 391-399 (2002).

17. Ando, H. et al. Purification and characteristics of a novel transglutaminase derived from microorganisms. Agric. Biol. Chem. 53, 2613-2617 (1989).

18. Miwa, N. Innovation in the food industry using microbial transglutaminase: Keys to success and future prospects. Anal. Biochem. 597, $113638(2020)$.

19. Heck, T., Faccio, G., Richter, M. \& Thöny-Meyer, L. Enzyme-catalyzed protein crosslinking. Appl. Microbiol. Biotechnol. 97, 461-475 (2013).

20. Isaschar-Ovdat, S. \& Fishman, A. Crosslinking of food proteins mediated by oxidative enzymes-A review. Trends Food Sci. Technol. 72, 134-143 (2018).

21. Quan, W. et al. Effects of small laccase from Streptomyces coelicolor on the solution and gel properties of whey protein isolate. LWT Food Sci. Technol. 101, 17-24 (2019).

22. Mattinen, M. L. et al. Effect of protein structure on laccase-catalyzed protein oligomerization. J. Agric. Food Chem. 54, 8883-8890 (2006).

23. Cura, D. E. et al. Laccase-aided protein modification: Effects on the structural properties of acidified sodium caseinate gels. Int. Dairy J. 19, 737-745 (2009).

24. Steffensen, C. L., Andersen, M. L., Degn, P. E. \& Nielsen, J. H. Cross-linking proteins by laccase-catalyzed oxidation: Importance relative to other modifications. J. Agric. Food Chem. 56, 12002-12010 (2008).

25. Oosterveld, A., Beldman, G. \& Voragen, A. G. J. Oxidative cross-linking of pectic polysaccharides from sugar beet pulp. Carbohyd. Res. 328, 199-207 (2000)

26. Voragen, A. G. J., Pilnik, W., Thibault, J. F., Axelos, M. A. V. \& Renard, C. M. G. C. Pectins. In Food Polysaccharides and Their Applications (ed. Stephen, A. M.) 287-339 (Marcel Dekker Inc, 1896).

27. Ralet, M. C., Thibault, J. F., Faulds, C. B. \& Williamson, G. Isolation and purification of feruloylated oligosaccharides from cell walls of sugar-beet pulp. Carbohyd. Res. 263, 227-241 (1994).

28. May, C. D. Industrial pectins: Sources, production and applications. Carbohydrate Polym. 12, 79-99 (1990).

29. Kuuva, T., Lantto, R., Reinikainen, T., Buchert, J. \& Autio, K. Rheological properties of laccase-induced sugar beet pectin gels. Food Hydrocolloids 17, 679-684 (2003).

30. Micard, V. \& Thibault, J. F. Oxidative gelation of sugar-beet pectins: use of laccases and hydration properties of the cross-linked pectins. Carbohydr. Polym. 39, 265-273 (1999).

31. Carvajal-Millan, E., Guilbert, S., Morel, M. H. \& Micard, V. Impact of the structure of arabinoxylan gels on their rheological and protein transport properties. Carbohydr. Polym. 60, 431-438 (2005). 
32. Claudia, L. E., Elizabeth, C. M., René, B. Q., Yolanda, L. F. \& Agustín, R. C. Pectin and pectin-based composite materials: Beyond food texture. Molecules 23, 942 (2018).

33. Jung, J. \& Wicker, L. Laccase mediated conjugation of sugar beet pectin and the effect on emulsion stability. Food Hydrocoll. 28, $168-173$ (2012).

34. Takei, T., Sugihara, K., Yoshida, M. \& Kawakami, K. Injectable and biodegradable sugar beet pectin/gelatin hydrogels for biomedical applications. J. Biomater. Sci. Polym. Ed. 24, 1333-1342 (2013).

35. Chen, B., Li, H., Ding, Y. \& Suo, H. Formation and microstructural characterization of whey protein isolate/beet pectin coacervations by laccase catalyzed cross-linking. LWT Food Sci. Technol. 47, 31-38 (2012).

36. Chen, H., Gan, J., Ji, A., Song, S. \& Yin, L. Development of double network gels based on soy protein isolate and sugar beet pectin induced by thermal treatment and laccase catalysis. Food Chem. 292, 188-196 (2019).

37. Chen, H. et al. New insights into the functionality of protein to the emulsifying properties of sugar beet pectin. Food Hydrocoll. 57, 262-270 (2016).

38. Qiu, S., Yadav, M. P. \& Yin, L. Characterization and functionalities study of hemicellulose and cellulose components isolated from sorghum bran, bagasse and biomass. Food Chem. 230, 225-233 (2017).

39. Zaidel, D. N. A., Chronakis, I. S. \& Meyer, A. S. Enzyme catalyzed oxidative gelation of sugar beet pectin: Kinetics and rheology. Food Hydrocoll. 28, 130-140 (2012).

40. Bakhsh, A. et al. A novel approach for tuning the physicochemical, textural, and sensory characteristics of plant-based meat analogs with different levels of methylcellulose concentration. Foods 10, 560 (2021).

41. De Angelis, D. et al. Physicochemical and sensorial evaluation of meat analogues produced from dry-fractionated pea and oat proteins. Foods 9, 1754 (2020).

42. Ayadi, M., Kechaou, A., Makni, I. \& Attia, H. Influence of carrageenan addition on turkey meat sausages properties. J. Food Eng. 93, 278-283 (2009).

43. Ismail, I., Hwang, Y.-H. \& Joo, S.-T. Interventions of two-stage thermal sous-vide cooking on the toughness of beef semitendinosus. Meat Sci. 157, 107882 (2019).

44. Kamani, M. H., Meera, M. S., Bhaskar, N. \& Modi, V. K. Partial and total replacement of meat by plant-based proteins in chicken sausage: Evaluation of mechanical, physico-chemical and sensory characteristics. J. Food Sci. Technol. 56, 2660-2669 (2019).

45. Sarkar, N. Thermal gelation properties of methyl and hydroxypropyl methylcellulose. J. Appl. Polym. Sci. 24, 1073-1087 (1979).

46. Sarkar, N. \& Walker, L. Hydration-Dehydration properties of methylcellulose and hydroxypropyl methylcellulose. Carbohydr. Polym. 27, 177-185 (1995)

47. Walstra, P. Physical Chemistry of Foods (CRC Press, 2002).

48. McClements, D. J., Weiss, J. W., Kinchla, A. J., Nolden, A. A. \& Grossmann, L. Methods for testing the quality attributes of plantbased foods: Meat- and processed-meat analogs. Foods. 10, 260 (2021).

49. Wang, Z. et al. Effect of the interaction between myofibrillar protein and heat-induced soy protein isolates on gel properties. CyTA-J. Food. 13, 527-534 (2015).

50. Patel, A. R., Schatteman, D., Lesaffer, A. \& Dewettinck, K. A foam-templated approach for fabricating organogels using a watersoluble polymer. RSC Adv. 3, 22900-22903 (2013).

51. Oh, I., Lee, J., Lee, H. G. \& Lee, S. Feasibility of hydroxypropyl methylcellulose oleogel as an animal fat replacer for meat patties. Food Res Int. 122, 566-572 (2019).

52. Guillon, F. \& Thibault, J. F. Further characterization of acid- and alkalisoluble pectins from sugar beet pulp. Lebensmittel Wissenschaft und Technologie 21, 198-205 (1988).

53. Nakauma, M. et al. Comparison of sugar beet pectin, soybean soluble polysaccharide, and gum Arabic as food emulsifiers. 1. Effect of concentration, pH, and salts on the emulsifying properties. Food Hydrocoll. 22, 1254-1267 (2008).

54. Zeeb, B., Fischer, L. \& Weiss, J. Cross-linking of interfacial layers affects the salt and temperature stability of multilayered emulsions consisting of fish gelatin and sugar beet pectin. J. Agric. Food Chem. 59, 10546-10555 (2011).

55. Zeeb, B., Gibis, M., Fischer, L. \& Weiss, J. Crosslinking of interfacial layers in multilayered oil-in-water emulsions using laccase: Characterization and pH-stability. Food Hydrocoll. 27, 126-136 (2012).

56. Zeeb, B., Salminen, H., Fischer, L. \& Weiss, J. Impact of heat and laccase on the $\mathrm{pH}$ and freeze-thaw stability of oil-in-water emulsions stabilized by adsorbed biopolymer nanoparticles. Food Biophys. 9, 125-137 (2014).

57. He, J., Evans, N. M., Liu, H. \& Shao, S. A review of research on plant-based meat alternatives: Driving forces, history, manufacturing, and consumer attitudes. Compr. Rev. Food Sci. Food Saf. 19, 2639-2656 (2020).

58. Young, V. R. \& Pellett, P. L. Plant proteins in relation to human protein and amino acid nutrition. Am. J. Clin. Nutr. 59, 1203S-1212S (1994).

59. Meade, S. J., Reid, E. A. \& Gerrard, J. A. The impact of processing on the nutritionalquality of food proteins. J. AOAC Int. 88, 904-922 (2005).

60. Fehér, A., Gazdecki, M., Véha, M., Szakály, M. \& Szakály, Z. A comprehensive review of the benefits of and the barriers to the switch to a plant-based diet. Sustainability 12, 4136 (2020).

61. Godfray, H. C. J. et al. Meat consumption, health, and the environment. Science 361, eaam5324 (2018)

62. Trowell, H. Dietary fibre, ischaemic heart disease and diabetes mellitus. Proc. Nutr. Soc. 32, 151-157 (1973).

63. Pathare, P. B. \& Roskilly, A. P. Quality and energy evaluation in meat cooking. Food Eng. Rev. 8, 435-447 (2016).

64. Wi, G., Bae, J., Kim, H., Cho, Y. \& Choi, M. J. Evaluation of the physicochemical and structural properties and the sensory characteristics of meat analogues prepared with various non-animal based liquid additives. Foods 9, 461 (2020).

65. Bühler, J. M., Dekkers, B. L., Bruins, M. E. \& van der Goot, A. J. Modifying faba bean protein concentrate using dry heat to increase water holding capacity. Foods 9,1077 (2020).

66. Doi, E., Shibata, D. \& Matoba, T. Modified colorimetric ninhydrin methods for peptidase assay. Anal. Biochem. 118, 173-184 (1981).

\section{Acknowledgements}

We would like to thank Editage (http://www.editage.jp) for English language editing. We thank Ms. Mari Hayakawa for supporting our experiments. We also thank Ms. Mao Morita for teaching the in-vitro gastrointestinal digestibility experiments.

\section{Author contributions}

K.S., Y.S., M.O., and S.Y. designed the experiments. K.S. performed all experiments and wrote the manuscript. All authors read and approved the final manuscript.

\section{Competing interests}

The authors declare no competing interests. 


\section{Additional information}

Supplementary Information The online version contains supplementary material available at https://doi.org/ 10.1038/s41598-021-96058-4.

Correspondence and requests for materials should be addressed to K.S.

Reprints and permissions information is available at www.nature.com/reprints.

Publisher's note Springer Nature remains neutral with regard to jurisdictional claims in published maps and institutional affiliations.

(c) (1) Open Access This article is licensed under a Creative Commons Attribution 4.0 International cc) License, which permits use, sharing, adaptation, distribution and reproduction in any medium or format, as long as you give appropriate credit to the original author(s) and the source, provide a link to the Creative Commons licence, and indicate if changes were made. The images or other third party material in this article are included in the article's Creative Commons licence, unless indicated otherwise in a credit line to the material. If material is not included in the article's Creative Commons licence and your intended use is not permitted by statutory regulation or exceeds the permitted use, you will need to obtain permission directly from the copyright holder. To view a copy of this licence, visit http://creativecommons.org/licenses/by/4.0/.

(C) The Author(s) 2021 